\title{
Observaçōes preliminares sobre o sagüi, Callithrix humeralifer intermedius (Hershkovitz, 1977) em Dardanelos, rio Aripuanà, Mato Grosso
}

\author{
Anthony B. Rylands (")
}

\section{Resumo}

A Callithrix humeralifer intermedius ocorre entre os rios Roosevelt e Aripuană, no sul da Amazônia. Este trabalho apresenta observaçōes preliminares sobre o C.h. intermedius em ambiente natural de maio a novembro de 1978, em Dardanelos. Eles vivem na floresta primária densa, secundária e campinarana. O tamanho do grupo varia de 4 a 13 indivíduos, sendo que os maiores possuem mais do que um par de adultos. A área de uso de um grupo observado por 160,5 horas era de 13,75 hectares e durante este período percorriam entre 740 e $1500 \mathrm{~m}$ durante o dia. Sua dieta inclui pequenos frutos, flores, resinas e insetos. Os grupos foram observados com um par de infantes durante os meses de setembro e outubro, ou seja no fim da estação seca. Alguns aspectos do comportamento social e predadores potenciais são descritos.

\section{INTRODUÇÁO}

Os sagüis do gênero Callithrix são quase totalmente brasileiros em sua distribuição. Das 3 espécies e 11 subespécies reconhecidas por Hershkovitz (1977), apenas uma, C. argentata melaneura, estende-se pela Bolívia e Paraguai. Nos últimos anos, Callithrix e Ságuinus têm-se tornado cada vez mais importantes em pesquisas biomédicas, fisiológicas e etológicas (Kingston, 1972; Wolfe et al. 1972; Gengozian et al., 1977; Hearn et al., 1977; Stevenson, 1977). Algumas das subespécies de Callithrix têm distribuição muito restrita e será necessário tomarem-se algumas medidas no futuro próximo para a sua conservação. Apesar disso, praticamente nada se conhece a respeito do seu comportamento e ecologia na vida selvagem.

Cailithrix humeralifer intermedius foi des. crito pela primeira vez por Hershkovitz em 1977, a partir de um espécime (fêmea adulta) obtiøio pelo Museu Goeldi, Belém, Pará, na boca do rio Guariba em 1975, e 2 espécimes (macho adulto e fêmea adulta), obtidos pelo Instituto Evandro Chagas, Belém, Pará, de Aripuanã no rio Roosevelt, em 1974 (Fig. 1) .

Em janeiro de 1978, foram iniciados os levantamentos iniciais para um estudo de cam. po de $C$. h. intermedius, baseado no Núcleo Pioneiro Humboldt do Instituto Nacional de Pesquisas da Amazônia (INPA), em Dardanelos, no rio Aripuanã. Este trabalho é um relatório de algumas observações feitas durante maio, julho, setembro e parte de outubro de 1978 , as quais compreendem o início de um estudo que continuará até outubro de 1979.

Dada a sua descoberta recente, estão incluídas uma breve descrição de $C$. $h$. interme. dius e sua distribuição em relação a outras subespécies de $C$. hemeralifer.

\section{DISTRIBUIÇÃo}

A distribuição de C. h. intermedius está limitada ao oeste do rio Aripuanã, ao sul da boca do rio Guariba, ocorrendo ao leste do rio Roosevelt (Fig. 1). C.h.chrysoleuca e C.h. hemeralifer ocorrem ao norte, entre os rios Madeira-Aripuanã e Canumã, e os rios Canumã e Tapajós, respectivamente (Hershkovitz, 1977). O local mais ao sul atualmente conhecido onde ocorre C.h.chrysoleuca é Prainha, no rio Aripuanã, ao norte da boca do rio Roosevelt.

Os limites das distribuições das subespé. cies de $C$. humeralifer não são conhecidos. Hershkovitz (1977) propõe que tanto C. $h$. chrysoleuca quanto $C$. h. humeralifer podem ocorrer tanto ao sul quanto às cabeceiras do rio Aripuanã, entre os rios Aripuanã e Juruena. Em adição, ele afirma que $C$. argentata mela-

(*) - Instituto Nacional de Pesquisas da Amazônia, Manaus 
neura é simpátrico com $C$. h. intermedius ao oeste do rio Aripuanã. Tanto $C . h$. intermedius quanto C. a. melaneura ocorrem em Dardanelos. C. h. intermedius está confinado ao oeste do rio Aripuanã, conforme proposto por Hershkovitz (1977), mas C. a. melaneura está limitado ao leste e sua distribuição conhecida estende-se a $10^{\circ} \mathrm{S}$, entre os rios Aripuanã e Ju-

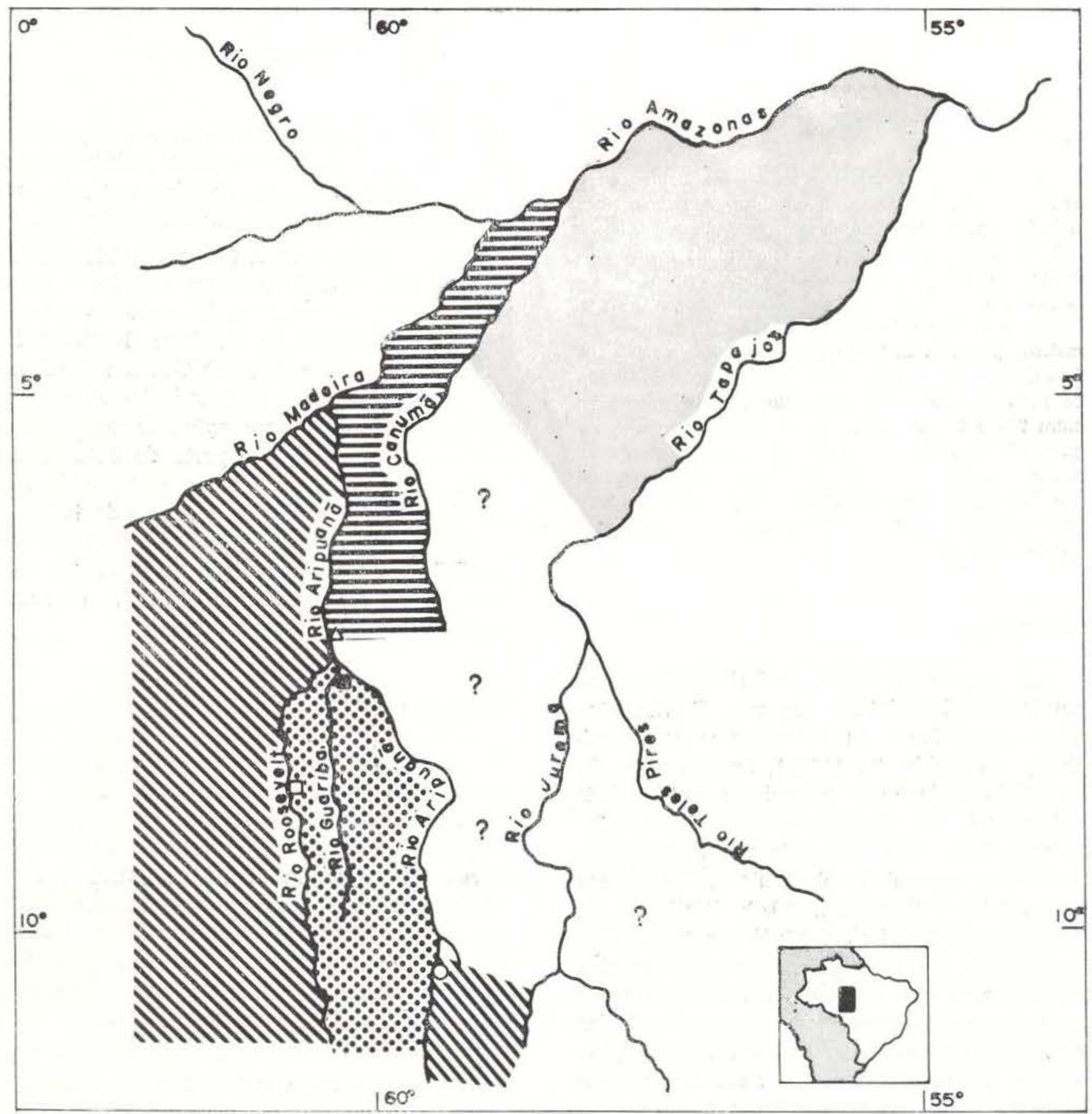

Fig. 1 - Distribuições de Callithrix humeralifer e uma parte de C.a.melaneura no Brasil. Modificado a partir de Hershkovitz (1977)
$\triangle$ Prainha.
Aripuanā, rio Roosevelt.
- Foz do rio Guariba.
O Dardanelos.

Callithrix hemeralifer humeralifer.

C.h.chrysoleuca.

C. h . intermedius.

C. argentada melaneura. 
ruena. Não existe evidência de ocorrência de outras subespécies de $C$. humeralifer na regiăo, e a cabeceira do rio Canumã é provavelmente o limite sul das distribuições de $C . h$. humeralifer $\in$ C. $h$. chrysoleuca.

\section{DESCRIÇÃo}

C. h. intermedius é, como o nome sugere, intermediário em coloração entre o escuro C. h. humeralifer e o pálido C. h. chrysoleuca. Os ombros, parte superior dos braços, gargante e parte superior do tórax, são de cor branca. Sobre a cabeça, entre as orelhas, existe uma faixa acinzentada. Os braços, do cotoveio às mãos, são levemente mais escuros. A cara $\odot$ orelhas são rosadas, sendo que as orelhas săc apenas levemente tufacias de branco. A parte de cima das mãos e pés são cinza prateado. As palmas e solas são escassamente pigmentadas. O dorso é claro, castanho avermeihado. A região mais baixa das costas é manchada de castanho escuro ou laranja escuro até à base da cauda. As manchas do quadril, características do grupo de sagüis $C$. argentata, são alaranjadas e estendem-se ao longo da parte superior das coxas e na parte interna das pernas num padrão idêntico, mas ligeiramente menos distintas do que $C$. melaneura que ocorre na margem leste do rio Aripuanã, em Dardanelos. A cauda é clara com padrões individuais variáveis de manchâs e anéis pouco distintos. O abdome é alaranjado.

De acordo com Hershkovitz (1977) a cauda do espécime obtido no rio Guariba tem anéis pouco distintos ao longo do comprimento. Isto não ocorre nc $C$. h. intermedius de Dardanelos, no qual os anéis são evidentes apenas na base da cauda ou, às vezes, na ponta.

\section{ÁRFA DE ESTUdo E MÉTOdos}

Foi escolhida uma área de estudo a 3 $\mathrm{km}$ ao sudoeste da margem esquerda do ric Aripuanã, oposta a Dardanelos $\left(10^{c} 10^{\prime} \mathrm{S}\right.$.. $59^{\circ} 27^{\prime}$ W., altitude de $203 \mathrm{~m}$. acima do nível do mar) em janeiro de 1978. Em fevereiro e março subseqüentes, um sistema de cami nhos, em quadrados de $10 \mathrm{~m} \times 100 \mathrm{~m}$, foi desbastado em 60 ha., para facilitar a observação de 7 grupos de $C . h$. intermedius. No mês seguinte, 20 ha. foram subdivididos para a formação de caminhos de $50 \mathrm{~m}$, cobrindo a área de uso de um grupo (arupo A) para possibilitar sua observação durante o dia.

Durante abril, e nas duas primeiras semanas de maio, o grupo A foi seguido até acos. tumar-se à presença do observador a uns $15-20 \mathrm{~m}$. Durante a segunda metac'e de maio, julho e setembro seguintes, este grupo foi observado num total de 160,5 horas, e as informações foram obtidas com relação à distância percorrida por dia, tamanho e utilização da área de uso, comportamento alimentar, interações de grupo e comportamento social. Os individuos são reconhecíveis face às marcas variáveis da cauda. A cada 5 minutos, a identidade, atividade e posição em relação ao habitat de todos os indivíduos à vista, era registrado por um minuto. Contudo, estes dados ainda náo foram analisados.

Outros primatas que ocorrem na área de estudo são Callicebus moloch donacophilus Saimiri sciureus, Cebus apella e C. albifrons, Pithecia monachus, Chiropotes a!binasus, Ateles paniscus chamek, Lagothrix lagothricna cana e Alouatta. Aotus trivirgatus provavelmente ocorre na área, mas nunca foi observado.

\section{HABITAT}

Os habitats, na área de estudo incluem: a) florestas secundárias novas e velhas; b) floresta alta com uma canópia quebrada e um denso estrato médio e cipós em abundância e c) floresta primária com uma canópia mais fechada, um estrato médio mais escasso e menos abundante em cipós. A distribuição do grupo " $A$ " inclui todas as 3 categorias. Contudo, embora os dados não tenham sido analisados, é evidente que a maior parte do tempo de atividade do grupo é passada nos primeiros dois tipos de floresta. Entre setembro de 1977 e abril de 1978, foram feitos 46 levantamentos em uma trilha através da floresta primária do terceiro tipo, num terreno ondulado, perfazendo um total de 61 horas. Nem Callicebus moloch nem $C$. h. intermedius foram observados nesta trilha. Parece que am- 
bos requerem áreas de vegetação densa, sejam florestas secundárias velhas, florestas relativamente novas, ou, pelo menos, florestas primárias que tenham sido parcialmente mexidas.

As distribuições de 2 grupos de $C$. $h$. intermedius sobrepõem-se numa densa floresta baixa (năo mais alta do que $16 \mathrm{~m}$ ) sobre areia branca, que possivelmente é equivalente às florestas de campinarana de areia branca do baixo rio Negro. Embora Caliicebus moloch ocupe o mesmo habitat que $C$. h. intermedius na área de estudo, ele ocupa apenas marginalmente esta mancha de floresta de areia branca.

\section{TAMANHO E COMPOSIÇÃo DO GRUPO}

C. h. intermedius foi observado em grupos, cujo tamanho variava entre 4 e 13 . O tamanho e composição de 4 grupos, para os quais foram realizadas contagens seguras e repetidas em setembro de 1978, são dados na tabela 1. Os tamanhos dos grupos estão entre 8 e 12, compreendendo mais de um par de adultos em todos os casos. Estes resultados podem ser comparados com os de Izawa (1978) para Saguinus nigricollis na Colômbia. O tamanho do grupo variava entre 4 e 8 e em apenas um dos 10 grupos existiam mais do que 3 adultos. Thorington (1968) registrou tamanhos de grupos entre 2 e 4 em 7 grupos de S. midas. Um oitavo grupo de 6 foi considerado por Thorington estar em processo de divisăo. Neyman Warner (1978), contudo, observou grupos de S. oedipus de tamanhos semelhantes aos de $C$. h. intermedius.
Indivíduos ou mesmo pares foram observados, às vezes, solitários, mas em muitas ocasiões eventualmente reuniam-se com um grupo. No grupo " $A$ " os indivíduos e pares foram observados alimentando-se de insetos e viajando separadamente do grupo principal por até 50 minutos.

\section{REPRODUÇÃo E DESENVOLVIMENTO DO JOVEM}

De acordo com Hershkovitz (1977), a época de nascimento para Callithrix é no final da estação seca ou no início da estação úmida, e a época de acasalamento é do final da estação úmida ao início da estação seca. Mas em julho de 1977, no meio da estação seca, os indivíduos mais jovens observados em qualquer dos grupos eram um pouco maiores do que a metade do tamanho do adulto. Por comparação com os dados de crescimento de Pook (1976) para C. a. argentata em cativeiro, estimou-se que esses jovens deveriam ter 3-4 meses de idade. Filhotes recém-nascidos foram vistos pela primeira vez em 3 grupos em setembro de 1977, no final da estação seca. Outros grupos foram vistos com filhotes em outubro e novembro de 1977. Nunca foi observado mais do que um par de filhotes num grupo.

C. jacchus tem cio pós-parto e, em cativeiro, tem a capacidade de reproduzir duas vezes por ano (Hearn et al., 1977). Contudo somente Heltne (1978) admite a probabilidade dessa ocorrência na vida selvagem. O período de gestação em C. jacchus é de 144 dias (variação 141-146) e o intervalo entre os nas-

TABELA 1 - Tamanho e composição do grupo. Estimativas feitas em setembro de 1978. Subadulto: Aproximadamente do tamanho de um adulto, mas com pelagem incompleta. Jovem: Locomovendo-se independentemente; $1 / 2$ a $1 / 3$ do tamanho de um adulto. Filhote: Geralmente nas costas de um adulto, mais de $1 / 2$ do tamanho do adulto. Indivíduos adultos do grupo "A", mencionados no texto, estão entre parênteses.

\begin{tabular}{|c|c|c|c|c|c|c|c|}
\hline Grupo & Macho adulto & Fêmea adulta & Subadulto & Jovent & Filhote & Desconhecido & Total \\
\hline \multirow[t]{2}{*}{ A } & 3 & 4 & 1 & 1 & 2 & 0 & 11 \\
\hline & (2R, PT, ST) & (BR, BT, GT, WT) & & & & & \\
\hline B & 3 & 3 & 2 & 1 & - & 3 & 12 \\
\hline C & 2 & 1 & 1 & 2 & 一 & 3 & 09 \\
\hline 1 & 2 & 2 & 1 & - & 2 & 1 & 08 \\
\hline
\end{tabular}


cimentos pode ser só alguns dias mais (Hearn et al., 1977). Observando-se, em maio de 1977, muitos grupos com filhotes que tinham a idade estimada entre 3 e 4 meses e a ocor. rência de recém-nascidos na maioria dos grupos entre setembro e novembro indicam que há duas altas de nascimento durante o ano em conexão com o fenômeno mencionado acima: A primeira alta sendo no início da época de chuva (setembro-novembro) e a segunda no meio da época de chuva (fevereiro-abril).

Durante maio de 1978, o infanto juvenil, que tinha uma idade estimada de 2-3 meses, era muito independente, mas, às vezes, era visto mamando e sendo carregado nas costas do macho adulto $(2 R)$. Sua locomoçã̃o não era perfeita e. em várias ocasiões, ele pareceu incapaz de conservar-se com o grupo e, gritando, teve que ser apanhado pelo macho adulto $2 \mathrm{R}$. As vezes, ele ficava "estacionado", permanecendo quieto na forquilha de uma árvore por mais de uma hora, enquanto o grupo se alimentava a mais de $250 \mathrm{~m}$ de distância. Em julho e setembro de 1978, o infanto-juvenil foi considerado jovem. Não foi observado mamando ou nas costas do macho adulto $2 R$, embora freqüentemente viajasse perto dele. Durante maio e setembro de 1978, o macho adulto $2 \mathrm{R}$ foi freqüentemente observado caçando, agarrando, apertando e mordendo o infanto-juvenil assim como o subadulto. Estas são interações de brincadeiras, conforme descrito por Stevenson (1976) e Stevenson \& Poole (1976) para C. argentata.

Os filhotes do grupo " $A$ " nasceram na primeira semana de setembro de 1978. Eram freqüentemente vistos nas costas de um macho adulto ST e de uma fêmea adulta WT. O macho adulto PT e a fêmea adulta BT também foram observados carregando-os. Durante a segurda metade de setembro, eles foram observados sendo carregados separadamente. Não é possivel dizer com que freqüência eles mamavam durante esse período, mas geralmente eram vistos mamando 3.4 vezes por dia, com um máximo de 6 . Freqüentemente, pareciam ter relutância em deixar as ccstas de um adulto. Em uma ocasião, por exemplo, um sfilhote esforçou-se para permanecer nas costas de um macho aduito que pulava repetidamente entre 2 galhos, puxando e tentando morder o filhote que eventualmente foi empurrado para um galho onde se dependurou pre. cariamente por 3 minutos, gritando, antes de ser recolhido pela fêmea adulta WT. Em 10 de outubro, contudo os filhotes foram observados voluntariamente deixando as costas dos adultos e passando períodos curtos rastejan. do e gritando ao longo dos galhos. O desenvolvimento da locomoção, contudo, processouse rapidamente a partir daí e, em 20 de outubro, eles foram observados correndo ao iongo dos galhos e dando pequenos saltos entre gathos com alguma confiariça.

A copulação e o comportamento definidamente associado com a mesma não foram observados. Em 4 ocasiōes, em maio de 1978. os adultos foram vistos apresentando suas genitálias, de um modo descrito por Epple (1967) para C. jacchus. Duas vezes um macho foi observado mostrando a genitália para uma fêmea e duas vezes a fêmea para o macho. Os individuos foram vistos lambendo e cheirando a geníália do animal que a apresentava. Contudo, em C. jacchus isto pode ser um comportamento agressivo, sexual ou apenas associado com o estabelecimento de contato entre indivíduos (Epple, 1967). Não é possível dizer em qual contexto este comportamento foi efetuado em C. h. intermedius.

\section{COMPORTAMENTO DE MOBILIDADE E ATIVIDADE}

Contando-se todos os quadrados de $50 \mathrm{~m}$ x $50 \mathrm{~m}$ utilizados pelo grupo " $A$ " durante as observaçōes neste período, a área de uso é calculada em 13,75 ha. A observação do grupo B forneceu uma área de 12,5 ha mas isto, sem dúvida, é uma subestimativa. O grupo "A" era ativo, por cerca de 10 horas, cada dia, entre 6:30 e 16:30 h. Entre 16:30 e 17:00 h, o grupo estava geralmente acomodado em uma árvore de dormir. Por 10 dias, em setembro de 1978, o grupo foi seguido durante o dia e a distância viajada ficava entre 1100 e $1500 \mathrm{~m}$, exceto em duas ocasiōes quando o dia de atividade era de $740 \mathrm{~m}$ e $930 \mathrm{~m}$. Nesses dias, o grupo alimentou-se de insetos acima de um enxame de formigas de correição, Eciton burchelli, por $3: 17$ horas e $4: 42$ horas respectivamente, reduzindo a distância viajada. 
A utilização da área de uso é medida, calculando-se o tempo passado em cada um dos quadrados de $50 \mathrm{~m} \times 50 \mathrm{~m}$. Conforme foi mencionado acima, um tempo maior é passado em áreas de vegetação densa, alimentando-se de insetos, do que em florestas mais altas com um estrato médio mais escasso. Mais tempo é passado alimentando-se de insetos do que repousando/catando ou alimentando-se de frutos ou flores. Contudo, a rota seguida durante o dia é de alguma extensão, dependendo da localização das árvores frutíferas. Em maio e julho, por exemplo, era evidente que a procura de insetos era orientada nos arredores da localização de árvores de Cecropia com frutos. Em setembro, as áreas de procura de insetos estavam próximas de outras árvores com frutos.

Períodos curtos de inatividade ocorriam durante o dia todo, mas eram mais prolongados por volta de meio dia, entre 11:30 e 13:00 h. Freqüentemente, esses momentos de catação/repouso ocorriam em locais também usados para dormir. Os locais de dormir são geralmente árvores com uma densa cobertura de cipós. A altura em que eles se acomodam está geralmente entre 10 e $20 \mathrm{~m}$, mas pode ser tão alto quanto $28 \mathrm{~m}$ ou em vegetação densa baixa, a 5-6 m. Eles também foram observados utilizando um buraco em uma árvore morta de Coupia glabra, numa altura de $21,5 \mathrm{~m}$.

\section{COMPORTAMENTO ALIMENTAR}

c. h. intermedius foi observado comendo frutos, flores, resina de árvores, insetos, aranhas, lagartos e sapos. Uma relação de espécies de plantas identificadas, utilizadas por C. h. intermedius, é dada na tabela 2 .

Uma grande parte de cada dia era passada na alimentação com insetos. Isto podia ser feito enquanto os animais se moviam através da área de uso ou permaneciam em um local por mais de uma hora dispersos em 30-40 m. Eles geralmente procuram insetos na vegetação densa, na camada média da floresta, entre alturas de 3 a $16 \mathrm{~m}$. Buscam o alimento entre folhas mortas e vivas, em cavidades em gaIhos, em troncos de árvores $e$, às vezes, colo- cam as cabeças perto dos galhos e olham ao longo deie, provavelmente para obter perfis de insetos camuflados.

Durante dois dias, em setembro de 1978, eles alimentaram-se em cima de um enxame de formigas Eciton burchelli cupiens, as alturas de $0,5-3 \mathrm{~m}$, mas iam para o solo para coletar insetos perturbados pelas formigas. Estas formigas tinham uma picada bastante dolorosa, mas afora freqüentes coceiras, sacudidas e esfregadelas para remover as formigas que andavam sobre eles, não pareciam aborrecidos. Contudo, em uma ocasião, um macho adulto apanhou um grande gafanhoto com muitas formigas em seu corpo, bateu o gafanhoto duas vezes contra um galho, removendo algumas das formigas, mas depois jogou-o, sacudindo as mãos vigorosamente e esfregando-as no galho. Seu comportamento mostrou que ele sentia um certo desconforto.

Grandes gafanhotos, grilos, cigarras, baratas e mariposas são comidos, primeiro, pela cabeça, seguindo-se os intestinos. As asas das baratas, gafanhotos e cigarras não são comidas. Eles também comem lagartas, pequenos besouros e escaravelhos. Uma vez, uma fêmea adulta foi vista comendo um pequeno lagarto, de cerca de $4 \mathrm{~cm}$ de comprimento incluindo a cauda. A cabeça foi mordida primei. ro e ela então começou a comê-lo pela cabeça e uma das patas. Normalmente, quando se alimentam de sapos, eles comem a maior parte do corpo, porém, somente uma vez o cérebro foi comido.

A maioria das frutas comidas por $C . h$. intermedius são pequenas. Eles comem a polpa ao redor das sementes. Frutos pequenos são mordidos ou arrancados da árvore, e são então segurados em uma ou ambas as mãos enquanto são comidos. Frutos muito pequenos são comidos inteiros. Se a semente é grande, é jogada fora.

Frutos grandes, como os de Cecropia, Theobroma e Inga são comidos enquanto ainda presos à árvore.

Humiria balsamifera foi encontrado apenas na parte da floresta de areia branca ocupada em parte pelo grupo C. Este grupo foi observado alimentando-se extensivamente de 
TABELA 2 - Espécies de plantas utilizadas por C. humeralifer intermedius. Também säo mostradas as partes das plantas comidas e os meses durante os quais C.h. intermedius e outras espécies de primatas que foram observadas alimentando-se das mesmas.

\begin{tabular}{|c|c|c|c|c|}
\hline Espécies & Familia & Farte comida & Meses & $\begin{array}{l}\text { Outros primatas observados utilizado } \\
\text { as espécies }\end{array}$ \\
\hline Humiria balsamifera & Humiriaceae & Fruto & Maio-Julho & - \\
\hline Cecropia sciadophylla & Moraceae & Fruto & Maio-Julho & $\begin{array}{l}\text { Callicebus moloch; Cebus apella; Ateles } \\
\text { paniscus. }\end{array}$ \\
\hline Prunus myrtifolia & Rosaceae & Fruto & Abril-Maio & Callicebus moloch. \\
\hline Coupia glabra & Celastraceae & Fruto & Maio & - \\
\hline Bocageopsis multiflora & Annonaceae & Fruto & Abril-Maio & Cebus apella. \\
\hline Guatheria pteropus & Annonaceae & Fruto & Maio-Setembro & $\rightarrow$ \\
\hline Vismia cayenensis & Gutiferae & Fruto & Maio & - \\
\hline Não identificado & Meliaceae & Fruto & Maio & Callicebus moloch. \\
\hline Cordia sellowiana & Boraginaceae & Fruto & Setembro & $\begin{array}{l}\text { Callicebus moloch; Cebus apella; Cebus } \\
\text { albifrons. }\end{array}$ \\
\hline Pourouma palmata & Moraceae & Fruto & Julho-Outubro & $\begin{array}{l}\text { Callicebus moloch; Cebus apella; Lago- } \\
\text { thriz lagothricha; Ateles paniscus. }\end{array}$ \\
\hline Inga rubiginosa & Leguminosae & Fruto & Agosto-Setembro & $\begin{array}{l}\text { Callicebus moloch; Cebus apella; Cebus } \\
\text { albifrons; Ateles paniscus. }\end{array}$ \\
\hline Inga $\mathrm{sp}$. & Leguminosae & Fruto & Agosto-Setembro & Cebus apella; Ateles paniscus. \\
\hline Theobroma speciosum & Sterculiaceae & Fruto & Outubro-Novembro & Cebus apella; Ateles paniscus. \\
\hline Mendoncia aspera & Mendonciaceae & Fruto & Outubro & $\rightarrow$ \\
\hline Mendoncia aspera & Mendonciaceae & Flores & Maio-Junho & - \\
\hline Synphonia globulifera & Gutiferae & Fiores & Setembro & - \\
\hline Enterolobium meximum & Leguminosae & $\begin{array}{l}\text { Resina da } \\
\text { vagem }\end{array}$ & Maio-Julho & 一 \\
\hline Guarea sp. & Meliaceae & $\begin{array}{l}\text { Resina do } \\
\text { tronco }\end{array}$ & Maio-Outubro & 一 \\
\hline Parkia pendula & Leguminosae & $\begin{array}{l}\text { Resina do } \\
\text { tronco }\end{array}$ & Setembro-Outubro & - \\
\hline
\end{tabular}

3 árvores de Humiria, de maio a julho, enquanto outros grupos se alimentavam de frutos de Cecropia.

As flores de Symphonia globulifera e um cipó, Mendoncia, também eram comidos. As duas espécies têm flores vermelhas e foram comidas extensivamente. As pétalas, ou corolas em forma de tubo de Mendoncia, são re. movidas e o ovário é comido.

Infreqüentemente, $C$. h. intermedius foi observado comendo resina de árvores. Este comportamento é característico de Callithrix e Cebuella e eles tem dentes incisivos adaptados para isso (Rosenberger, 1978). A resina de 4 espécies de árvores foi comida, uma das quais permanece não identificada. As vi- sitas a essas árvores eram breves e, em muitas ocasiões, envolvem só algumas mordidas perfunctórias na casca da árvore, seguidas por marcação dos buracos, no caso de Enterolobium e Guarea. O número de buracos visíveis em 3 árvores de Guarea na área de uso do grupo $A$ era de 14,6 e 23 , em alturas entre 6 e $21 \mathrm{~m}$.

Uma árvore de Enterolobium na área de uso do grupo " $A$ " foi usada mais intensamente, durante maio e julho 1978 . Nove cavidades onde os animais se alimentavam eram visiveis nessa árvore. O maior tempo em que um indivíduo foi observado alimentando-se em um desses buracos foi de 9 minutos. Nunca mais do que 4 individuos do grupo foram observa- 
dos na árvore em qualquer momento. As alturas em que se alimentavam estavam entre 8 e $30 \mathrm{~m}$.

Durante setembro e outubro, o grupo " $A$ " foi observado alimentando-se da resina exsudada da casca das vagens de Parkia pendula. Essas vagens de sementes ficavam penduradas em cachos em longos caules. Os sagüis comem a resina descendo os longos caules para alcançar as vagens ou de um galho próximo mais conveniente ou de vagens caídas que se tenham alojado no estrato médio ou na vegetação baixa. As alturas para alimentação de vagens presas à árvore estavam entre 28 e $40 \mathrm{~m}$.

\section{Comportamento DE marcaÇÃo PELO CHEIRo}

Epple (1975) descreveu 3 tipos de comportamento em sagüis ligados à marcação do meio ambiente pelo cheiro, associado como o uso do odor produzido por glândulas na pele e na área circungenital, glândulas suprapúbicas e glândulas do externo (Fig. 2). Estes comportamentos foram observados em $C . h$. intermedius.

a. Marcação com as glândulas circungenitais. Isto se efetua numa posiçăo sentada. O ânus é esfregado no substrato de um lado para outro. Os galhos săo marcados deste modo, mas este comportamento é mais evidente na marcação de buracos escavados em troncos de árvores e galhos para a obtençảo de resina, como descrito por Coimbra-Filho \& Mittermeier (1976). Este comportamento foi observado em ambos os sexos. Algumas vezes, eles urinavam ao mesmo tempo. Esta forma de marcação pelo cheiro também é usada para marcar galhos onde os sagüis estiveram sentados ou catando.

b. Marcação com as glândulas suprapúbicas. O sagüi deita-se ao longo de um galho ou tronco de árvore com o estômago e área genital comprimidos contra ele, arrastando para a frente usando os pés ou as mãos ou ambos. Essa maneira de deitar-se do animal não envolve necessariamente uma atitude de marcação pelo cheiro, mas pode ser apenas uma posição de relaxamento. A marcação pelo cheiro pode freqüentemente proceder ou seguir essa posição relaxada. Este é o mais freqüentemente observado dos comportamentos de marcação pelo cheiro, especialmente quando o grupo se move ao longo da mesma rota de árvores, quando cada indivíduo em seu turno marca um lugar num galho ou outro lugar próximo. A marcação com as glândulas suprapúbicas as vezes, é feita, ao mesmo tempo, que a marcação com as glândulas do esterno, em um só movimento.

c. Marcação com as glândulas do esterno. Este comportamento é semelhante ao que envolve a marcação com as glândulas suprapúbicas, mas o peito e o queixo são empurrados ao longo do substrato, com os quartos traseiros levantados. Observou-se que isto precede imediatamente a marcação com as glândulas suprapúbicas, empurrando o peito e o queixo para a frente ao longo do substrato, e então pressionados os quartos traseiros para baixo e arrastando para a frente em uma ação contínua. Os galhos frequientemente usados como rotas de viagem são marcados deste modo e podem ser repetidamente marcados conforme cada indivíduo vai passando.

Outras formas de marcação pelo cheiro e auto-unção com urina não foram observados freqüentemente. Estas incluem o esfregamento de um galho com a parte de dentro dos braços de um modo lento e distinto, urinando no galho e então esfregando o ânus no galho e urinando com a cauda enrolada levemente de maneira a interceptar a urina. A marcação de indivíduos da mesma espécie foi observada infreqüentemente durante $o$ repouso e catação. Uma fêmea adulta, por exemplo, pode esfregar seu ânus para cima e para baixo no flanco de um adulto macho enquanto está sendo catada. Em uma outra ocasião, uma fêmea subadulta foi vista agachando-se à aproximação de um macho adulto, que subseqüentemente estendeu-se sobre a fêmea e permaneceu nessa posição por cerca de 3 segundos. Isto pode ter envolvido a marcação com as glândulas do esterno.

É evidente que o cheiro é depositado no substrato nessas ocasiōes em que os indivíduos podem parar e cheirar ou lamber um local marcado por outro. As vezes, um indivíduo pode passar sobre um local marcado e então voltar para cheirar, lamber a marca de cheiro. 


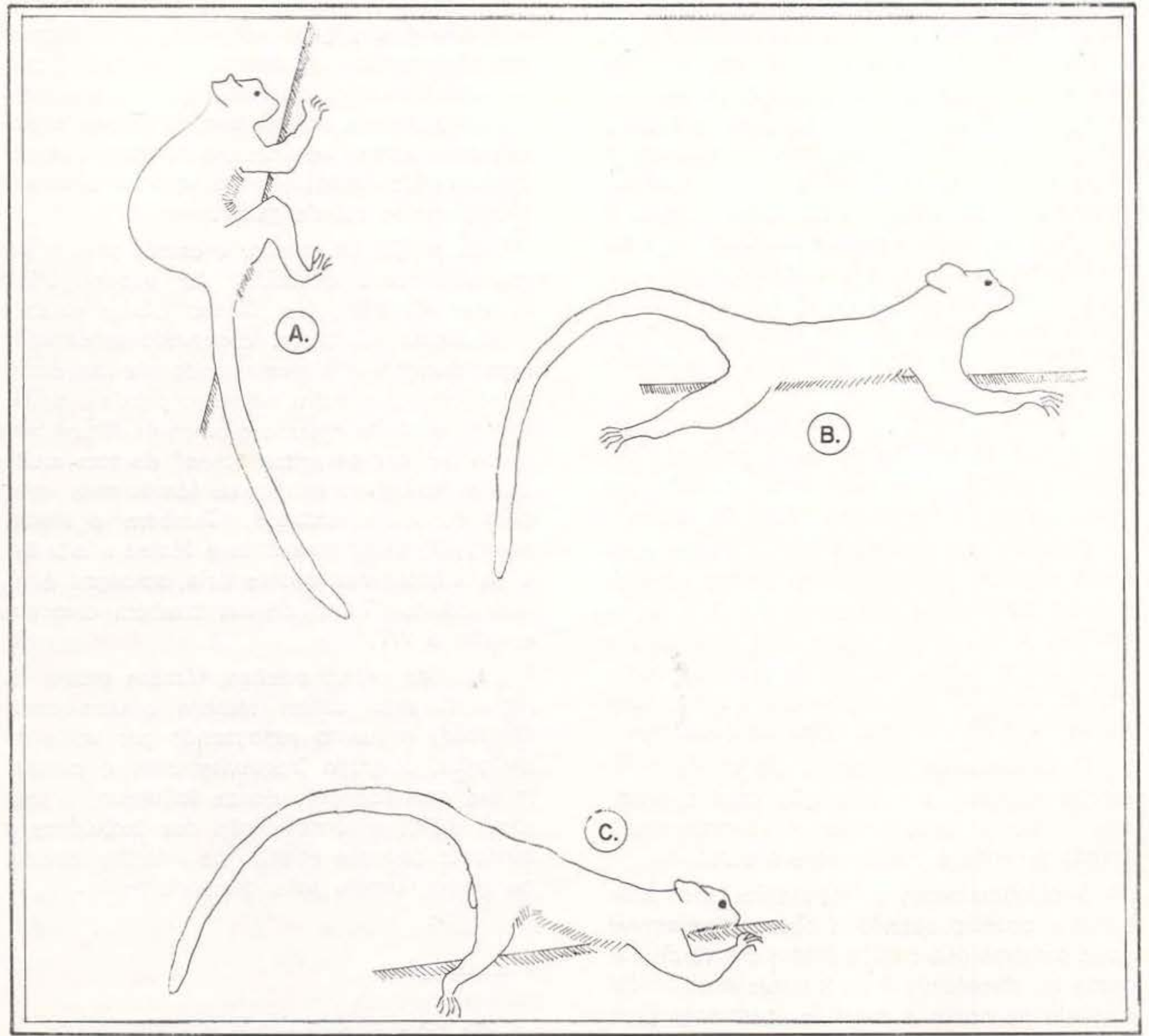

Fig. 2 - Posturas adotadas por C.h.intermeaius durante a marcação com o cheiro: a. Marcação de um buraco nc tronco de uma árvore com as glândulas circungenitais em seguida ao ato de comer a resina do buraco; b. Marcaçẩo de um galho com as glândulas suprapúbicas, e c. Marcáção de um galho com as glândulas do esterno.

\section{ENROLAMENTO DA CAUDA}

Moynihan (1970) discute padrões complexos de enrolamento de cauda em Saguinus cedipus geoffroyi em pormenores e acredita que é importante na comunicação visual. Enrolamento de cauda com formas de complexidade descrita por Moynihan não foi observado em $=$ C. $h$. intermedius, mas isso pode ser devido às dificuldades de observação nas condições do estudo de campo.
A forma mais freqüente de enrolamento de cauda ocorre quando eles estão relaxados ou repousando. A cauda é colocada entre as pernas e enrolada no sentido do comprimento. Isto é visto, mais freqüentemente, no final da tarde quando eles estão situados numa ár. vore de dormir. Uma postura de dormir característica envolve o enrolamento da cauda deste tipo, com o sagüi abaixando-se de modo que a cauda enrolada fique ao longo de seu flanco ou ligeiramente sobre as costas. A 
cauda nessa posição também ajuda na sustentação (Hershkovitz, 1977). O enrolamento de cauda semelhante pode ser efetuado mas não de uin modo relaxado. A cauda é trazida para entre as pernas com um movimento rápido, enrolada e embalada nos braços enquanto o sagüi se abaixa, obviamente tenso, olhando atentamente ao redor e arranhando a cauda a intervalos, de modo rápido e excitado. Isto foi observado durante intensas trocas vocais entre grupos e, em outras vezes, quando o grupo estava se comportando de maneira excitada por alguma razão não identificada pelo observador.

Durante interaçōes intensivas entre grupos, a metáde trazeira da cauda pode ser enrolada enquanto a cauda está mantida um pouco acima de horizontal, atrás do corpo.

Uma posição de cauda para a frente, conforme descrito por Moynihan (1970) para S. oedipus também foi observada em $C$. $h$. intermedius. A cauda é mantida reta mas para a frente sob o corpo, em vez de relaxada numa posição vertical. Não é possivel dizer se isto é algo mais do que uma ajuda no equilíbrio.

O enrolamento da ponta da cauda pode ocorrer durante a auto-unção com a urina, mas também precedendo 0 arranhamento quando a cauda é trazida para o corpo.

O chicoteamento da cauda foi observado em uma ocasião quando o observacior estava muito próximo dos sagüis (entre 5 e $10 \mathrm{~m}$ ) A cauda foi chicoteada 2 ou 3 ve $z$ is e então foi enrolada na pontá e mantida levemente fara a frente por uns poucos segundos. A impressão dada foi que essa era uma reação zarvosa à aproximação do observador.

\section{Catação}

Períodos de catação podem ocorrer durante o dia, mas são mais freqüentement€ observados encr: 11:30 13:00 h. Um indivíduo pode aproximar-se de outro e abaixar-se ac lado deste convidando-o à catação ou ser catado sem qualquer solinitação aparente. O catador geralmente começa pela cabeça e pescoço, catando atravśs do pelo, repartindo-o com as mãos e ocasionalmente catando com a boca. O anim ! que está sendo catacio deita no galho, levantando os braços e pernas, submetendo-se a puxões vigorosos pelo catador em várias partes do corpo. A catação é muito cuidadosa. O animal catado pode eventualmente deitar de costas com os braços e pernas espalhados. Às vezes, a catação pode ser interrompida repentinamente quando o anima! catado quase cai do galho.

Os papéis de catador e catado podem ser repentinamente trocados. As vezes podem ocorrer disputas. Um macho adulto catando uma fêmea adulta foi observado ameaçando repetidamente a fêmea quando ela iria começar a catar um outro indivíduo próximo a ela. $\mathrm{O}$ macho adulto agarrou o braço da fêmea, soltando um par de gritos "tsee" de tom muito alto e puxando a cabeça da fêmea para baixo para continuar catando. Também o macho adulto ST, enquanto catava a fêmea adulta WT e os filhotes naj costas dela, ameaçou a fêmea adulta BT quando ela também começou a catar $r$ WT.

Machos catam machos, fêmeas catam fêmeas, macho: catam fêmeas e vice-versa. Contudo, enquanto repousando por volta de meio-dia, o grupo freqüentemente é parciaimente ocultado pela densa folhagem, o cue torna difícil a identificação dos indivíduos e qualquer deducão relativa às relações sociais nu grupo durante este comportamento.

\section{VocALIZAÇốES}

As vocalizações de $G$. h. interniedius são inuito variadas e a mair 'a de' $s$ é semelhante às dos pás uns, possuind: equivalentes muito próximos comunidade le pássaros de Aripuanã. Possíveis rezôtes para isto são propostas por Vencl (1C77). Enhthora os tipos básicos de vocalizą̧óes possam ser recorihecidos, e'es variam $\mathrm{rm}$ intensidade altura $\mathrm{e}$ modo 3 repetição. As vocalizayõns scguintes são desc "itas usando-se z : ierninologia de Epple (1968)

a. Gritos de contato. Os mais ́́bvios dos gritos de contato são os lorgos gritos "phee", dados geralmente 2 vezes em sucessão, mas freqüentemente numa seqüência de 4 ou 5 . às vezes, seguidos por um "gorjeio" descendente. Estes são os mais altos dos gritos dados 
por C. h. intermedius. Períodos de vocalização deste tipe ocorrem quando o grupo está bastante disperso. Um indivíduo isolado que solte esses gritos fica atentamente à espera de gritos de resposta, e vira a cabeça rapidamente para olhar na direção da origem do grito. Periodos prolongados de gritos deste tipo estão freqüentemente associados com a repentina queda de chuva e ocorrem durante encontros intergrupais. Na última situação, os gritos "phee" deste tipo são intensos e mais freqüentemente seguidos por "gorjeios" descendentes. Epple (1968) também observou que esses gritos eram usados em comunicação intergrupal por $C$. jacchus em cativeiro.

Gritos "phee" intermitentes e mais calmos, únicos ou duplos, são ouvidos durante o dia, embora mais freqüentemente nas manhãs e no final das tardes. Epple (1968) registra que esses chamados podem ser dados sempre quando os membros do grupo estejam sem contato visual.

Gritos "phee" muito fracos, curtos e individuais foram ouvidos ocasionalmente. São descritos por Epple (1968) como ocorrendo sempre que os animais estão perturbados ou em próximo contato visual. Em C. $h$. intermedius este grito pode ser pronunciado entre gritos "phee" altos dados por indivíduos separados e também em conjunção com gritos "tsik" e tosse ('ock'), quando perturbados pelo observador (ver abaixo).

a. Gritos de "Mobbing". O tipo e intensidade de gritos dados por C. h. intermedius em resposta ao observador ou predadores potenciais varia. Em situaçōes de baixa excitação, os gritos proferidos incluem '"tsik", "phee" fracos e tosse ('ock'), freqüentemente dados em seqüência nessa ordem. No grupo " $A$ ", esses gritos ainda podem ser dados seguindo um repentino movimento do observador. Além disso, eles podem dar um complexo grito de tom baixo ou estridente, o qual é acompanhado por uma rápida protrusão rítmica da língua. Epple (1968) descreve algo semelhante para C. h. argentata argentata num alio estado de excitação. Stevenson (1976) também menciona sesta rápida protrusăo rítmica da língua por C. argentata durante brincadeiras ou catação. Esta protrusão da língua não é pronunciada como em Saguinus fuscicollis conforme observado por Stevenson (1976), ou em Saguinus bicolor (obs. pessoal).

Em situações de alta excitação, tais como encontros com a irara, Eira barbara, ou falcöes da floresta, uma rápida sucessão de aitos gri. tos "tsik" é pronunciada. Esta resposta é também provocada pelo observador em grupos que não estão habituados, embora a resposta de baixa excitação seja mais usual.

c. Gritos de aviso. Assobios curtos de tom alto são dados brevemente ao súbito apa. recimento do observador ou de um predador. Isto é classificado como um grito de aviso por Epple (1968) e em C. h. intermedius é invariavelmente seguido por gritos "tsik" de Mobbing".

d. Vocalizações do filhote. Enquanto permanecem nas costas de um adulto, os filhotes geralmente estão silenciosos. Contudo, durante os esforços do adulto para removê-los, eles dão uma complexa série contínua de vocalizações que podem ser calssificadas coletivamente como gritos, mas contém repetidos gritos "tsik" e "assobios", assim como longos "gritos". Essas vocalizações, segundo Eppie (1968), ocorrem quando o filhote está em desconforto, isto é, ao menos, subjetivamente verdadeiro para $C$. h. intermedius. Muitas vezes em que se observaram as mamadas, elas eram precedidas por estes gritos. Na idade de cerca de 5 semanas, os filhotes do Grupo " $A$ " foram observados arrastando-se, dando pequenos pulos e agarrando-se mutuamente, 0 que provavelmente era um comportamento de brincadeira. Este era acompanhado por gritos quase contínuos. Com 6-7 semanas, eles eram capazes de mover-se com maior agilidade e os gritos eram apenas intermitentes.

O infanto-juvenil, observado durante abril e maio de 1978, gritava após ser "estacionado" por algum tempo, durante a brincadeira com um adulto e durante tentativas de o macho adulto $2 \mathrm{R}$ removê-los de suas costas.

\section{Agressão E ENCONTROS AGONÍSTICOS}

Os encontros agonísticos foram observados pouco freqüentemente durante o repouso ou a cataçãc. Ameaças agressivas envolviam 
movimentos rápidos do agressor na direção a um outro indivíduo, fazendo caretas com a boca aberta e soltando repetidos gritos agudos "tsee". A resposta do indivíduo ameaçado inclui um grito de ameaça "tsee" em retorno, seguido por fuga; silêncio e o animal se abaixa; ou grito breve pode ser ou não seguido por fuga. Em várias ocasiões, um indivíduo foi observado arremessando-se sobre outro que havia acabado de apanhar inseto. As vezes isso resultou em gritos e a fuga do indivíduo com o inseto.

C. argentata melaneura apresenta a listra da coxa colorida de laranja na ameaça agressiva (Stevenson, in litt., 1977). C. h. intermedius também tem esta listra na coxa. Seu uso na ameaça agressiva não foi observado, mas a açăo é, sem dúvida, sutil e pode muito bem ser perdida no campo. Encontros agonísticos, durante o repouso ou catação, freqüentemente ocorrem enquanto os participantes estão orientados, lado a lado, e um indivíduo movendo-se em direção a outro em ameaça, tazia isto movendo-se obliquamente ao longo do gaIho. Nesta situação, a listra laranja da coxa é bem conspícua.

C. argentata argentata e C. jacchus utilizam a apresentação genital em ameaças agressivas (Epple, 1970. Stevenson, in litt., 1977). A apresentação genital observada em $C$. $h$. intermedius é descrita na seção de reprodução. Este comportamento pode ser agonístico, sexual ou estabelecimento de contato. Durante interações intensivas entre grupos, quando os grupos podem estar um em frente do outro, a uma distância de alguns metros, os sagüis podem mostrar a genitalia. A parte trazeira da cauda está enrolada e levantada e a genitalia orientada para outro grupo. Durante interações perto assim, "gorjeios" intensos e prolongados estão dados. Uma postura agressiva em arco e o andar em ameaça defensiva apresentada por $C$. argentata argentata e $C$. jacchus (Epple, 1967) não foi observada em C. h. intermedius.

\section{Predadores}

A resposta a predadores, em todos os casos observados, pode ser acuradamente des- crita como "Mobbing". Rápidas seqüências altas de gritos "tsik" são dados enquanto o sagüi se move excitadamente, de galho para galho, perto do predador. Pelo menos, uma parte do grupo pode acompanhar o predador por uma distância curta, conforme ele se retira. Tanto machos quanto fêmeas tem sido observados "Mobbing" desta maneira.

O "Mobbing" foi observado na direção de iraras (Eira barbara) e falcōes da floresta (Micrastur ruficollis).

Izawa (1978) observou Micrastur ruficollis com um Saguinus nigricollis em suas garras. Outras Micrastur spp. que ocorrem na área e que também podem ser capazes de predar C. h. intermedius são $M$. mirandollei, aproximadamente do mesmo tamanho que $M$. ruficollis, e o maior $H$. semitorquatus ( $\mathrm{P}$. Roth, com. pessoal, 1978; Schauensee, 1971). Águias, Harpia e Morphnus e Spizaetus, também ocorrem na região ( $P$. Roth, com. pessoal, 1978), mas nunca foram observadas pelo autor. Não se sabe se os falcões Cará-Cará (Daptrius americanus e $D$. ater) que ocorrem na região, são predadores de sagüis. A única resposta observada em $C$. $h$. intermedius quando $D$. americanus voa por sobre sua cabeça ou perto é o abaixamento, às vezes acompanhado por gritos de aviso ou "tsik" que não são dados, na rápida série, alta característica de "Mobbing". Esta resposta de abaixamento e gritos "tsik" também foi observado quando abutres, Cathartes ou Corapyps, tucanos Ramphastus, araras, Ara e rapinantes não identificados voam sobre suas cabeças. Também quando um par de tucanos (Selenidera maculirostris) afastou um sagüi que se alimentava de um cacho de frutos de Cecropia. Estes não são predadores prováveis de sagüis. Os tucanos contudo comem carne quando em cativeiro (Rutgers, 1965), mas Izawa (1978), que observou um grupo de 4-6 Ramphastus tucanus que viajavam com um grupo de Saguinus nigricollis, acredita que eles sejam lentos demais para apanhar os sagüis.

Eira barbara tem sido considerado um predador de Saguinus nigricollis (Izawa, 1978), $S$. midas midas (J. Jansen, com. pessoal apud Galef et al., 1978) e Sioedipus geoffroyi (N. Smith, com. pessoal apud Moynihan, 1970). Iraras não são freqüentemente observados na 
área de estudo, exceto durante a frutificação de Cacao, Theobroma, em outubro e novembro, Uxi, Endopleura uchi, em março e Imbauba, Cecropia sciadophylla, entre maio e julho. Foram observados comendo os frutos dessas árvores

O fruto de Cecropia sciadophylla também é comido intensamente por $C$. $h$. intermedius. Em um certo número de ocasiōes, iraras foram observados repousando imóveis em forquilhas de árvores de Cecropia com frutos. Uma vez. duas iraras foram observadas nesta posição e provocaram gritos de aviso e "mobbing" pelos sagüis, que deixaram a área sem comer qualquer fruto, para voltar 2 horas e 15 minutos mais tarde e encontrar as iraras exatamente nas mesmas posições. Talvez seja significativo que, para o observador, as iraras deita. dos ımóveis num galho de Cecropia sejam notavelmente semelhantes às folhas caídas de Cecropia e confundem-se com elas. Neste segundo encontro, uma fêmea adulta subiu numa Cecropia e cerca de $10 \mathrm{~m}$ de uma irara antes de percebê-la e, fugindo, soltando o grito de aviso, iniciou uma agitação de gritos "tsik" de "mobbing" no resto do grupo.

\section{AgRADECIMENTOS}

Agradeço aos Diretores do Núcleo Pioneiro Humboldt. Aripuanã, do Instituto Nacional de Pesquisas da Amazônia (INPA), pelo auxílio logistico contínuo. Também agradeço ao Professor P. A. Jewell e ao Dr. T. H. CluttonBrock pela supervisão do trabalho. Dra. Marlene Freitas da Silva e Dr. William Rodrigues do Departamento de Botânica, INPA, gentilmente identificaram as espécies vegetais alimentares e Paul Roth identificou as espécies de pássaros mencionados no texto. Dr. Norman Penny identificou a espécie de formiga. Meus agradecimentos a Paul Roth e José Márcio Ayres por muitas discussões úteis e a Paul Roth pela crítica de um esboço inicial do manuscrito.

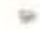

\section{SUMMARY}

The recently discovered Callithrix humeralifer intermedius, occurs between the rios Roisevelt and Aripua- nã in Brazil. It is intermediate in colouration between the dark C.h. humeralifer and the pale C.h. chrysoleuca. This paper presents some preliminary observations of $\mathbf{C . h}$. intermedius in the wild from May to November 1978. They occupy dense primary forest, second growth and low white sand forest. Group size is between 4 and 13, the larger groups comprising more than one adult pair. One group, watched for 160.5 hours occupied a home range of 13.75 ha. during this period, travelling between 740 and 1500 metres during the day. Principal foods include small fruits, flowers, tree exudates and insects. Groups were observed with one pair of newborn infants during September and October, at the end of the dry season. Observations of socia! behaviour (including agonistic behaviour, grooming, tail coiling behaviour and scent marking), development of young, vocalizations, and potential predators are described.

\section{BIBLIOGRAFIA}

Colmbra-Filho, A.F. \& Mittermeier, R.A.

1976 - Exudate-eating and tree gouging in marmosets. Nature, Lond. $262: 630$.

EPPLE, G.

1967 - Vergleichende Undersuchungen über sexual und socialverhalten der Krallenaffen (Hapalidae). Folia Primat. $7: 56-76$.

1968 - Comparative studies on vocalization in marmoset monkeys (Hapalidae). Folia Primat. $8: 1-40$

1970 - Quantitative studies on scent marking in the marmoset (Callithrix lacchus). Folia Primat. $13: 48-62$.

1975 - The behabiour of marmoset monkeys (Callithricidae). Primate Behaviour. $4: 195-239$.

Galef, G.G. J8.; Mittermeier, R.A. \& Balley, R.C. 1976 - Predation by the Tayra (Eira barbara). J. Mammal. $57: 760-761$.

Gengozinn, N.; Batson, J.S. \& SMith, T.A.

1977 - Breeding of marmosets in a colony environment. Paper presented at a conference "Marmosers in Experimental Medicine", March 16-18, 1977. OakRidge, Tennessee Ridge, Tennessee,

Hearn, J.P.; Abbott, D.H.; Chambers, P.C.; Hodges, J.K. \& LUNN, S.F.

1977 - Use of the common marmoset, Callithrix jacchus, in reproductive research. Paper presented at a conference "Marmosets in Experimental Medicine", March 16-18, 1977. Oak Ridge, Tennessee. 
HELTNE, P.G.

1978 - Demography and Wildlife Management of Tamarins and Marmosets. Prim. Med. 10: 30-36. S. Karger. Basel.

HeRshKOVITZ, P.

1977 - Living New World monkeys (Platyrrhini) with en introduction to primates. Vol. 1. University of Chicago Press. Chicago and London.

IZAWA, K.

1978 - A field study of the ecology and behaviour of the black-mantle tamarin (Saguinus nigricollis). Primates. $19: 241-274$.

Kingston, W.R.

1972 - Further observations on an established marmoset breeding colony. In Breeding Primates, ed. Beveridge W.I.B. S. Karger. Basel.

MOYNIHAN, M.

1970 - Some behaviour patterns of platyrrhine monkeys II. Saguinus geoffroyi and some other tamarins. Smithson. Contrib. Zool. $28: 1-77$.

NEYMAN-WARNER, P.F.

1978 - Aspects of the ecology and socict organization of free-ranging cotton-top tamarins (Saguinus oedipus) and the conservation status of the species. In The Biology and Conservation of the Callithricidae, ed. Kleiman D.G. Smithsonian Inst. Press. Washington D.C. in press.

Pook, A.G.

1976 - Development of hand-reared infantis of four species of marmoset. Jersey Wildlife Preservation Trust. 13th Ann. Report. 38-46

ROSENBERGER, A.L.

1978 - Loss of incisor enamel in marmosets. J. Mammal. 29 : 207-208.
RUTGERS, A.

1965 - The handbook of foregin birds in colour. Their care in cage and aviary. ㄷd. Norris K.A. Blandford Press, Loncion.

SCHAUENSEE, R.M. DE

1971 - A guide to the birds of South America. Oliver and Boyd Edinburgh.

SteVenson, M.F.

1976 - Behavioural observations on groups of Callithricidae qith an emphasis on playful behaviour. Jersey Wildlife Presenvation Trust. 13th Ann. Report. 47-52.

1977 - The common marmoset (Callithrix jacchus jacchus) as a model for ethological research. Lab. Anim. Sci. $27: 895-900$.

Stevenson, M.F. \& Poole, T.B.

1976 - An ethogram of the common marmoset (Callithrix jacchus jacchus): general behavioural repertoire. Anim. Behav. 24: 228-251.

THORINGTON, R.W. JR.

1968 - Observatinns of the tamarin Saguinus midas. Folia Primat. 9: 95-98.

VENCL, F

$$
\begin{aligned}
& 1977 \text { - A case of convergence in vocal signals } \\
& \text { between marmosets and birds. Amer. }
\end{aligned}
$$
Natur. $111: 777-782$

Wolfe, L.G.; Ogden, J.D.; Deinhardt, J.B.; Fisher, L., \& DeINHARdT, F.

1972 - Breeding and hand rearing marmusets for viral oncogenesis studis. In Breeding Primates. Ed. Beveridge W.I.B. S. Karger. Basel.

(Aceito para publicação em 20/06/79) 
Dratata.

"Obsenvacoso pretiminarcs sobre o sagli, Callithrix humeralifer"

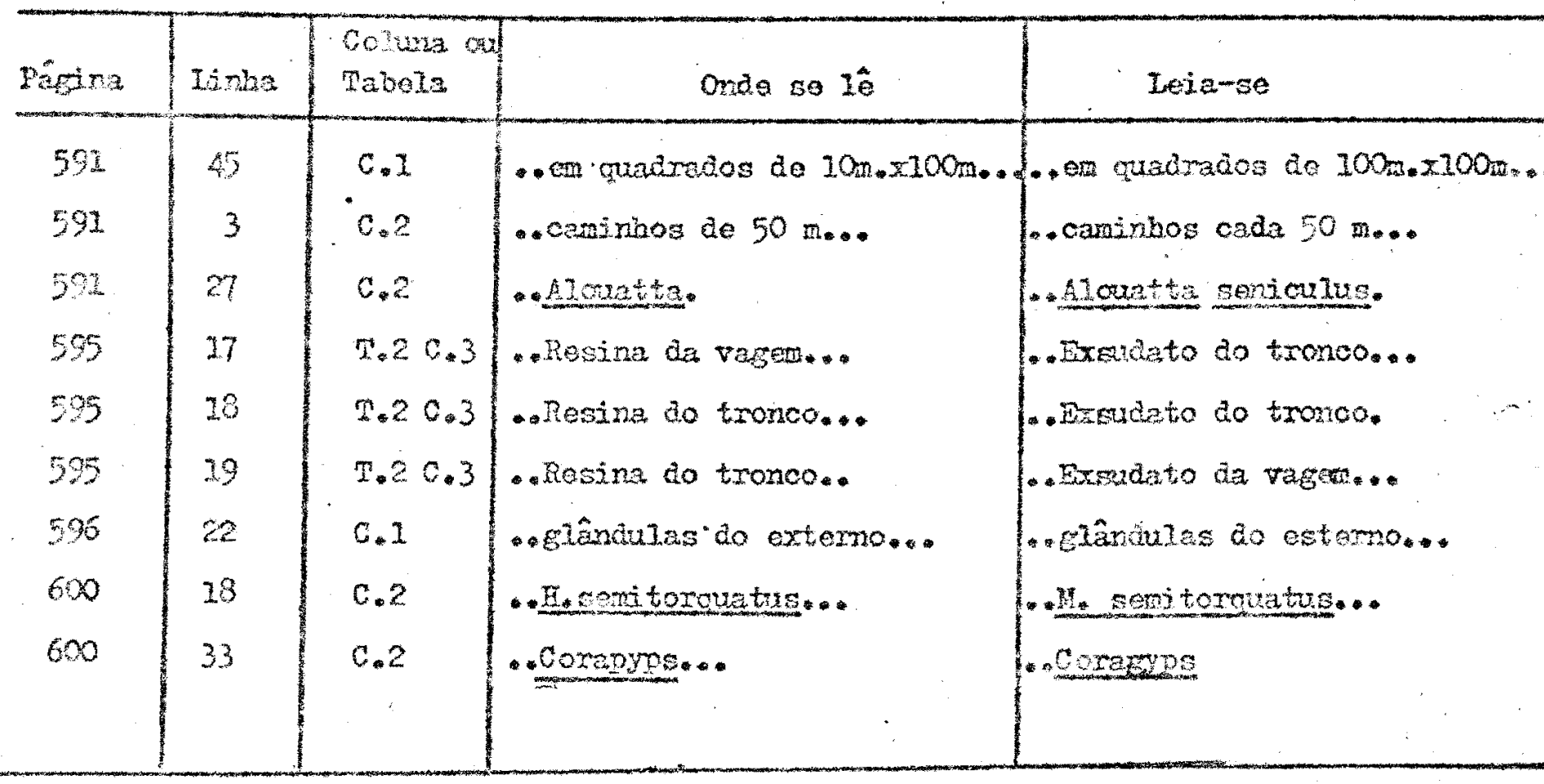

